BNL - 72180-2004-IR

CAP - 386-AES-03R

Informal Report

\title{
A Simplified Model of Multipactor Experiment for the Tunnel Dust Cholke
}

- Yongxiang Zhao

Physics Department

Brookhaven National Laboratory, Upton, New York

March 2004

\section{CENTER FOR ACCELERATOR PHYSICS}

BROOKHAVEN NATIONAL LABORATORY

BROOKHAVEN SCIENCE ASSOCIATES

Under Contract No. DE-AC02-98CH10886 with the

UNITED STATES DEPARTMENT OF ENERGY 


\section{DISCLAIMER}

This report was prepared as an account of work sponsored by an agency of the United States Government. Neither the United States Government nor any agency thereof, nor any of their employees, nor any of their contractors, subcontractors, or their employees, makes any warranty, express or implied, or assumes any legal liability or responsibility for the accuracy, completeness, or usefulness of any information, apparatus, product, or process disclosed, or represents that its use would not infringe privately owned rights. Reference herein to any specific commercial product, process, or service by trade name, trademark, manufacturer, or otherwise, does not necessarily constitute or imply its endorsement, recommendation, or favoring by the United States Government or any agency, contractor or subcontractor thereof. The views and -opinions of authors expressed herein do not necessarily state or reflect those of the United States Government or any agency, contractor or subcontractor thereof. 


\section{A Simplified Model of Multipactor Experiment for the Tunnel Dust Choke}

Yongxiang Zhao

Brookhaven National Laboratory

\section{THE ISSUE}

The SC-RF-gun project ${ }^{1}$ involves a cathode which requires thermal isolation from the niobium cavity body, mean while it is electrically a part of the cavity. Thus a choke is necessary. This kind of SC-RF-gun has been successfully made in FZR with a choke structure shown in Fig.(1). In considering its complexity, L. Phillips and J. Preble proposed an alternative -- tunnel dust choke structure-shown in Fig.(2), which is constituted by coaxial quart wavelength lines. This structure is simpler. However, the multipactor is a big concern. Because the outer conductor is parallel to the inner conductor, and the voltage between them is sinusoidal, there is very good chance to trigger multipactor.

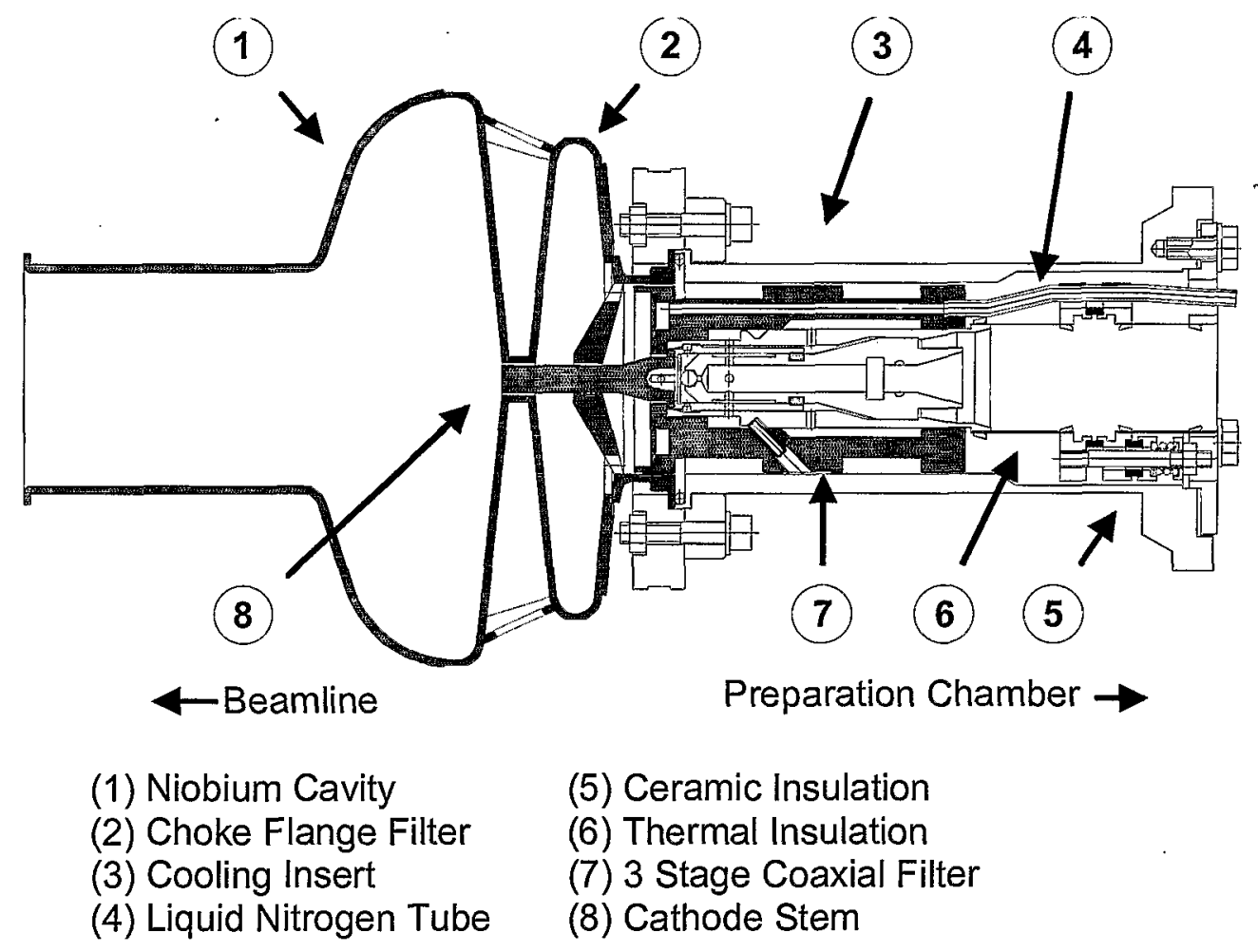

Fig.1 The FZR superconducting RF gun structure

There are many possible methods to depress multipactor. For example, coating tantalum nitride on the surface can reduce the second emission coefficient. However, the

\footnotetext{
${ }^{1}$ A project of AES-BNL collaboration.
} 
effectiveness of any measures has to be demonstrated. But, making a full scale experimental model requires huge driving power and is thus very costly and impractical.

To this end, a cost effective experimental model is highly desirable. This note is to address this issue.

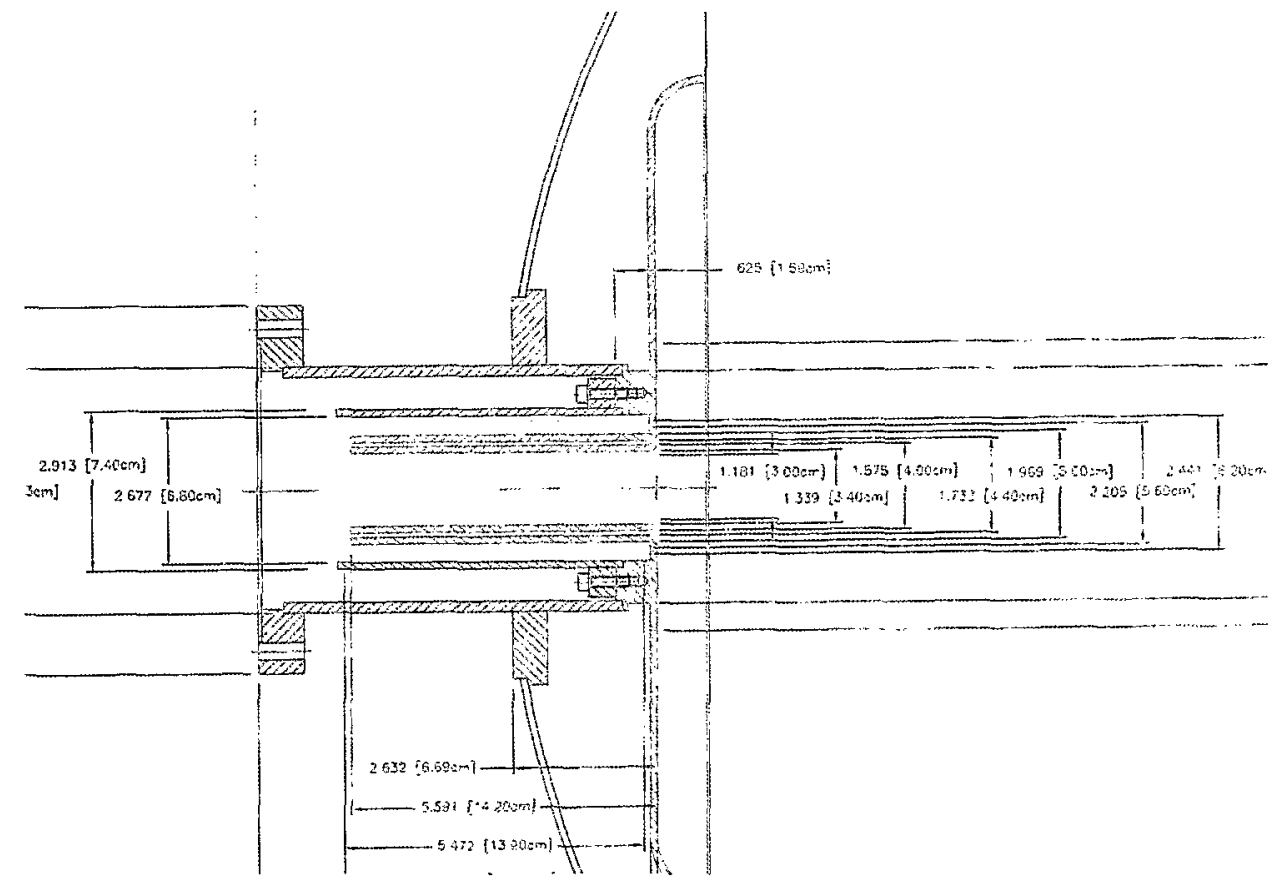

Fig.2 The tunnel dust choke structure

\section{THE BASIC REQUIREMENTS}

Our purpose is to check if there is multipactor inside the choke for the giving condition, but not in the cavity itself. In a real RF gun, most power is dissipated on the wall surface of the cavity, only a small amount is dissipated in the cathode-choke assembly.

If one designs an alternative cavity such that it keeps the same field inside the choke but reduces the field inside the cavity, then one can save power.

The field inside the choke fully depends on the current at the inlet. In fact, the choke assembly is a close space except an opening to the cavity, where is the only boundary driving the field inside the choke. In principle, the opening (or the inlet) of the choke should behaves as a short, providing the design is in good shape so as to minimize the influence to the field pattern of the cavity. Therefore, the input voltage at the inlet of the choke should be zero. Consequently, at the opening, only the current is the driving source of the inner field of the choke.

So, the sufficient and necessary condition is to design an apparatus which can supply the same current to the inlet of the choke. 


\section{THE BEST OPTION}

The cathode in a RF gun is located in the capacitive region, where the electric field is about the maximum, while the magnetic field is close to the minimum, so is the current.

In order to change the power distribution, the experimental model should be such that the choke is located about the maximum of the magnetic field. cavity.

There are many possible options. The simplest is a half wavelength coaxial line
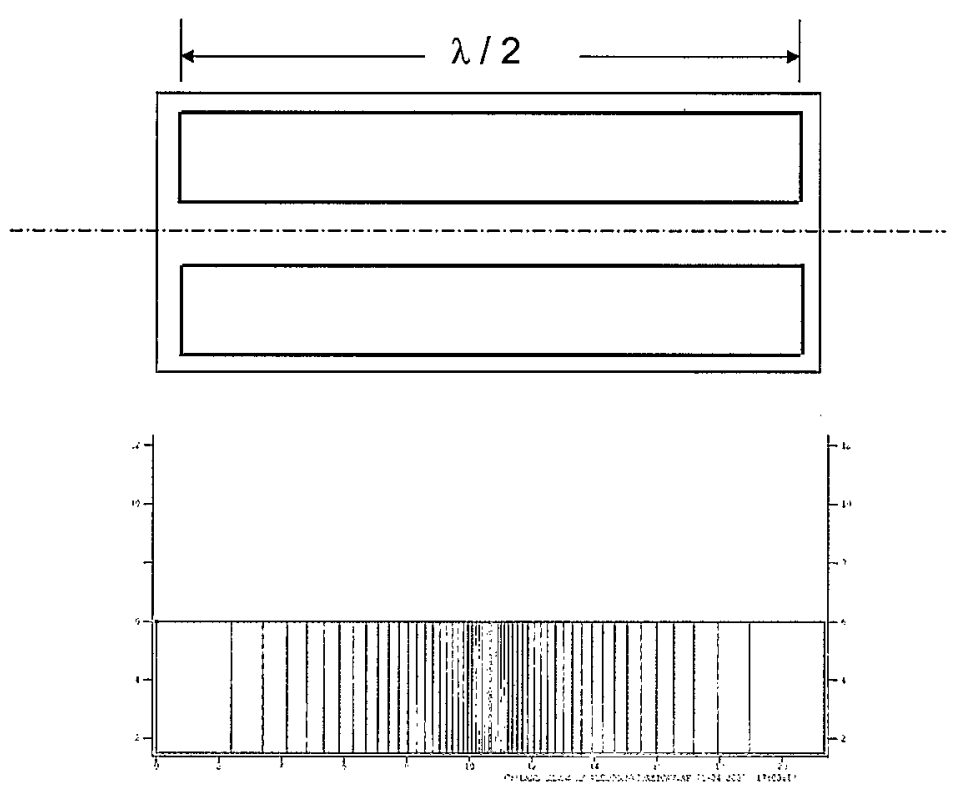

Fig.3 A simple half-wavelength coaxial line cavity and its electrical field pattern, where the low boundary in bottom view is the inner conductor.

Fig. 3 shows the cavity and electrical field pattern. If frequency is $703.4 \mathrm{MHz}$, then $\mathrm{L}$ $=\lambda / 2=21.34 \mathrm{~cm}$. Obviously, E-peak is on the center, while the current peaks are on both ends. A SUPERFISH run results in that the maximum current density at the end is $\mathbf{5 7 5 2}$ $\mathrm{A} / \mathrm{m}$ with a normalized electric field $1 \mathrm{MV} / \mathrm{m}$ at the center. This corresponds to a total power loss of $1884 \mathrm{~W}$.

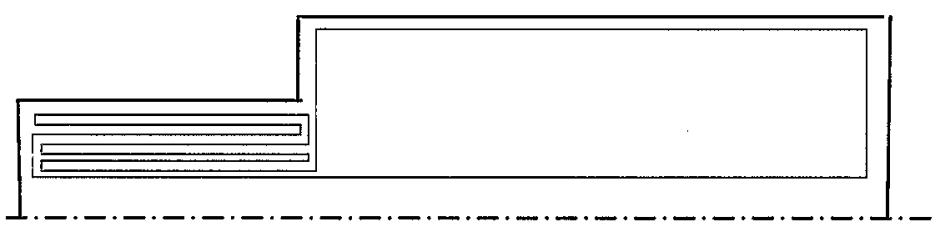

Fig.4 A coaxial line cavity with a choke (shown is only top half above the axis)

Fig.4 shows the schematic of such a coaxial cavity with a choke attached at the one end. The inner conductor is extended to the choke. Providing the choke is designed 
properly that the field pattern inside the main cavity has little affected, the current on the low left corner flows fully into the choke, while the voltage across the gap is zero. It is thus expected that a relatively small amount of driver power can deliver the same amount of current to the choke as that of the choke in the gun shown in Fig.2.

\section{NUMERICAL COMPARISON}

Fig.5 shows the resultant field pattern of SUPERFISH of the tunnel dust choke structure attached to a pill-box cavity. The cavity is not exact the same as shown in Fig.2, but the current distribution in the cathode area is not much different between them.

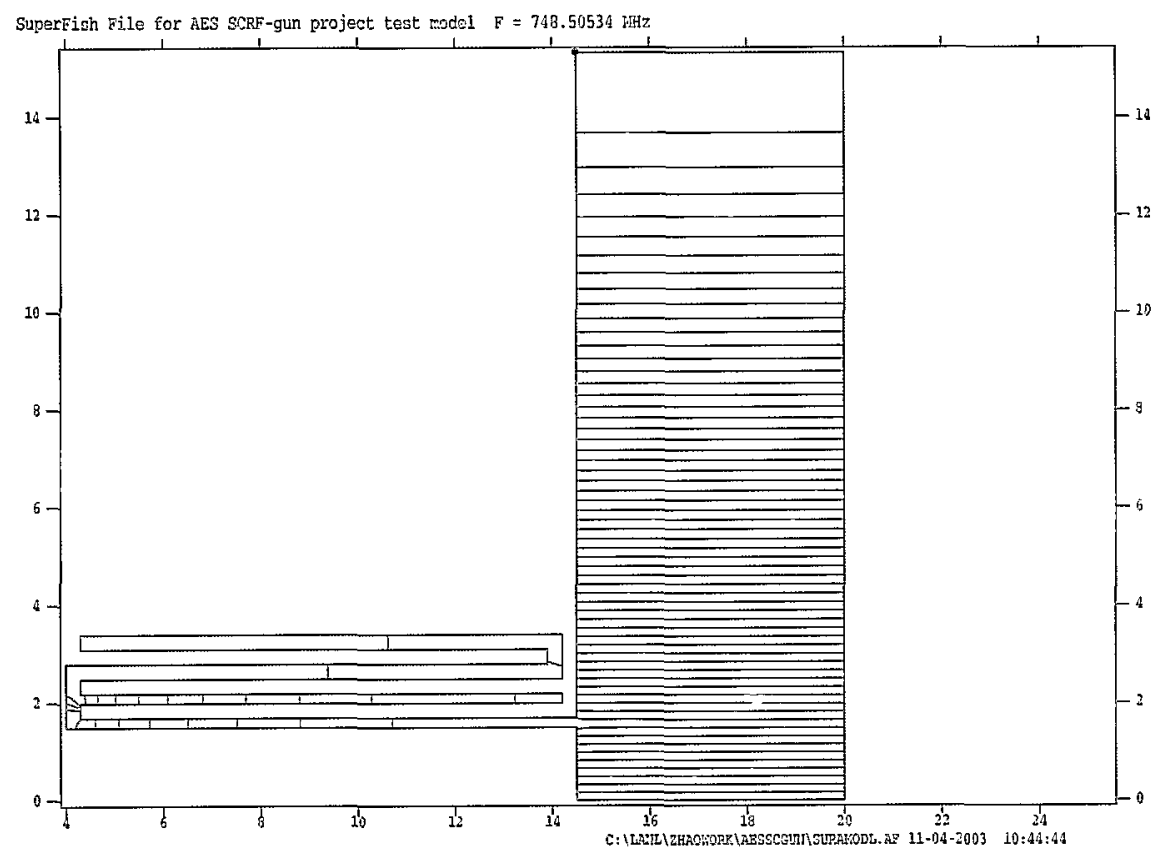

Fig.5 The field pattern of the pill-box cavity with a tunnel-dust choke

Fig.6 shows the similar SUPERFISH result of the coaxial line cavity with choke as mentioned above (Fig.4). Note that bottom line does not denote an axis but a radius of 1.5 $\mathrm{cm}$, which is the $\mathrm{r}_{-}$min defined in the input mesh file.

Table 1 gives the numerical comparison. These data are based on a normalized gradient of $1 \mathrm{MV} / \mathrm{m}$ in axis for Fig.5 and the center for Fig.6 respectively. It is clear from the last row that the current at the choke's inlet is much large in coaxial cavity than in the pill-box cavity.

Included is also the data of a simple coaxial cavity without choke. When a choke is involved in the coaxial cavity, the total loss is increased significantly from $1884 \mathrm{~W}$ to $4387 \mathrm{~W}$. It is because the current inside the choke has the same magnitude, while the surface area is even larger. Therefore the drive power is mostly lost inside the choke rather than in the main cavity, implying that the power is used more efficiently. 


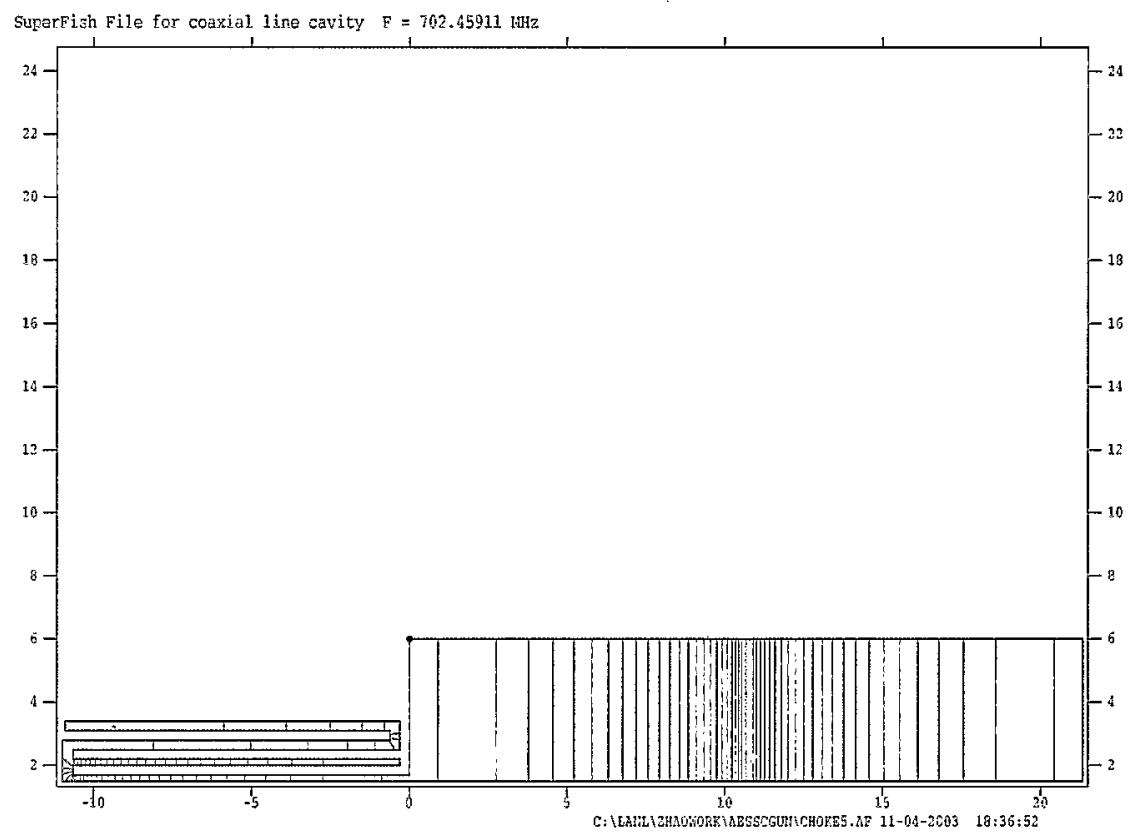

Fig.6 the field pattern of the coaxial line cavity with a tunnel-dust choke

Table 1 The power loss of different models

\begin{tabular}{|c|c|c|c|c|}
\hline Model & (Unit) & $\begin{array}{c}\text { Original Tunnel } \\
\text { Dust Choke } \\
\text { (Fig.5) } \\
\end{array}$ & $\begin{array}{c}\text { Coaxial } \\
\text { Cavity only } \\
\text { (Fig.3) } \\
\end{array}$ & $\begin{array}{c}\text { Coaxial cavity } \\
\text { with Choke } \\
\text { (Fig.6) } \\
\end{array}$ \\
\hline Frequency & $\mathrm{MHz}$ & 748.5 & 702.40 & 702.46 \\
\hline Normalization & & $1 \mathrm{MV} / \mathrm{m}$ & $1 \mathrm{MV} / \mathrm{m}$ & $1 \mathrm{MV} / \mathrm{m}$ \\
\hline Energy & Joule & $4.843 \mathrm{E}-3$ & $4.346 \mathrm{E}-3$ & $4.807 \mathrm{E}-3$ \\
\hline $\mathrm{Q}$ & & 16646 & 10183 & 4837 \\
\hline Power Loss & W & 1368 & 1884 & 4387 \\
\hline$E \max$ & $\mathrm{MV} / \mathrm{m}$ & 1.124 & 2.164 & 2.486 \\
\hline $\mathrm{H} \max$ & $\mathrm{A} / \mathrm{m}$ & 1580 & 5752 & 5757 \\
\hline 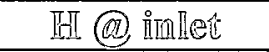 & $\mathbb{A} / \mathrm{mm}$ & 338 & & 5754 \\
\hline
\end{tabular}

Table 2 Original tunnel-dust model with different gradient

\begin{tabular}{|c|c|c|c|c|}
\hline Gradient & & $1 \mathrm{MV} / \mathrm{m}$ & $7 \mathrm{MIV} / \mathrm{Im}$ & $15 \mathrm{NIV} / \mathrm{m}$ \\
\hline Power Loss & $\mathrm{kW}$ & 1.368 & 67.03 & 307.8 \\
\hline$E_{\text {max }}$ & $\mathrm{MV} / \mathrm{m}$ & 1.124 & 7.868 & 16.86 \\
\hline H_max & $\mathrm{A} / \mathrm{m}$ & 1544 & 10808 & 23160 \\
\hline H@ inlet & $\mathrm{A} / \mathrm{m}$ & 338 & 2366 & 5070 \\
\hline
\end{tabular}


Table 3 The power required for a coaxial cavity with the same

\begin{tabular}{|c|c|c|c|c|}
\hline H @ inlet & $\mathrm{A} / \mathrm{m}$ & 5754 & 2366 & 5070 \\
\hline Field @ center & $\mathrm{MV} / \mathrm{m}$ & 1 & 0.411 & 0.881 \\
\hline Power Loss & $\mathrm{kW}$ & $\$ .387$ & $\mathbb{0} .782$ & 3.0101 \\
\hline E_max @ choke & $\mathrm{MV} / \mathrm{m}$ & 2.486 & 1.015 & 2.190 \\
\hline
\end{tabular}

Table 2 lists the power loss for different gradient of the real cavity. When gradient increases, the power increases squarely, while the current increases linearly.

Table 3 lists the corresponding power loss in the coaxial cavity with keeping the current at the choke's inlet being the same.

One can see from above tables that if the gradient of the gun requires $7 \mathrm{MV} / \mathrm{m}$. then the original cavity requires drive power of $67 \mathrm{~kW}$, and the current density of the choke is $2366 \mathrm{~A} / \mathrm{m}$. To keep the same current density, the coaxial cavity requires only a drive power of $0.742 \mathrm{~kW}$.

\section{COMMENTS}

It has been verified that a coaxial cavity can save a lot of power. However, two concerns are worthy to note.

1. The coaxial cavity itself may trigger multipactor. To this concern one may adopt one or more methods to depress the multipactor. Since the space is relatively larger, it is relatively flexible and has more options. The possible methods include coating, magnetic disturbance, or deforming the cavity shape. Fig.7 shows a possible deformation that gets rid of parallel surfaces.

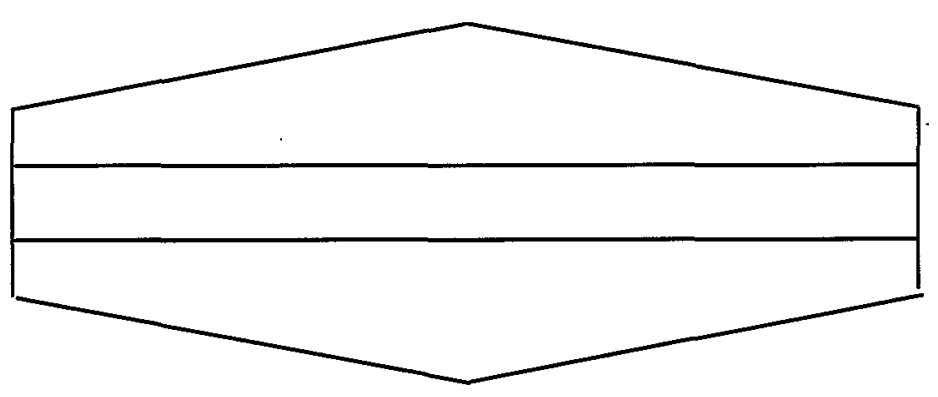

Fig.7 A deformed coaxial line half wavelength cavity

2. The above analysis has considered the fundamental current in the cathode. However, flowing in the cathode contains also abundant harmonics which also flow into the choke and establish harmonic voltages too. One must keep in mind to avoid the harmonic resonance in any choke. 